\title{
Exploring Concepts of Operations for On-Demand Passenger Air Transportation
}

\author{
Victoria Chibuogu Nneji*, Alexander Stimpson ${ }^{\dagger}$, and Mary (Missy) Cummings ${ }^{\ddagger}$ \\ Duke University, Durham, NC 27708 USA \\ and \\ Kenneth H. Goodrich ${ }^{\S}$ \\ NASA Langley Research Center, Hampton, VA 23681 USA
}

\begin{abstract}
In recent years, a surge of interest in "flying cars" for city commutes has led to rapid development of new technologies to help make them and similar on-demand mobility platforms a reality. To this end, this paper provides analyses of the stakeholders involved, their proposed operational concepts, and the hazards and regulations that must be addressed. Three system architectures emerged from the analyses, ranging from conventional air taxi to revolutionary fully autonomous aircraft operations, each with vehicle safety functions allocated differently between humans and machines. Advancements for enabling technologies such as distributed electric propulsion and artificial intelligence have had major investments and initial experimental success, but may be some years away from being deployed for on-demand passenger air transportation at scale.
\end{abstract}

\section{Introduction}

$\mathrm{T}$

HE idea of on-demand, personal air transportation has existed for some time and became popular with The Jetsons, a $20^{\text {th }}$ century cartoon about a family in the future that uses their 'car' to fly to work, shopping malls and diners. To date, the prospects for a practical family 'flying car' have come up short, despite consistent support. For example, the Small Aircraft Transportation System (SATS), proposed through a joint partnership between the National Aeronautics and Space Administration (NASA) and the Federal Aviation Administration (FAA), outlined a vision for increased use of fixed-wing single-piloted aircraft for personal transport ${ }^{1}$. However, the annual decline since 1980 in the number of private pilots licensed to operate in the United States ${ }^{2}$, the limitations of general aviation (GA) airport locations, challenges of air traffic management, and generally high costs of such aircraft proved to be insurmountable in realizing this vision ${ }^{3}$.

The rise of small unmanned aerial vehicles, coinciding with regulations supporting commercial drone operations ${ }^{4}$, has renewed hopes for the concept, now referred to as "On-Demand Mobility (ODM)." The goal of ODM is not necessarily to connect people between GA airports but rather to shorten the travel time within and between metropolitan regions by leveraging advanced vertical takeoff and landing (VTOL) designs and other technologies (e.g. vehicle autonomy and distributed electric propulsion) that were not sufficiently mature at the time of SATS.

New owner-operator models stemming from the ride-sharing automobile industry lead some to believe that these models will allow economic viability of ODM to provide rapid point-to-point air transportation. Table 1 depicts a matrix of six general models that illustrate different possible aircraft ownership and operational schemes, both current and future. The 'personal vehicle' is the standard model for those who operate their own aircraft, while commercial aircraft are used in the paid, scheduled transport operations we know of today. The 'corporate-piloted vehicle' includes private jets with hired operators who serve on the owner's schedule while the 'peer-to-peer shared vehicle' model is akin to borrowing an aircraft from a friend or via shared-ownership arrangements. 'Rental vehicles' provide alternatives to those with private pilot licenses who are deterred by the major financial investment

\footnotetext{
* Ph.D. Student, Duke Robotics, Box 90300144 Hudson Hall.

$\dagger$ Research Scientist, Duke Robotics, Box 90300144 Hudson Hall, AIAA Member.

* Professor, Duke Robotics, Box 90300144 Hudson Hall, AIAA Fellow.

$\S$ Aerospace Engineer, Dynamic Systems and Control Branch, MS 308, AIAA Senior Member.
}

1

American Institute of Aeronautics and Astronautics 
of personal aircraft ownership and maintenance. Finally, the one model in Table 1 that has gained recent attention is the 'transportation network vehicle' (TNV) model ${ }^{5}$, which relies on decentralized aircraft ownership and professional pilots, with potentially high vehicle utilization to help reduce cost.

Table 1: Ownership and operational models of air vehicles

\begin{tabular}{|c|c|c|c|}
\hline \multirow{2}{*}{ tain } & \\
\hline & Centralized Vehicle Ownership & Decentralized Vehicle Ownership & Self-Ownership \\
\hline 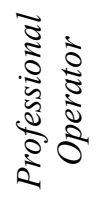 & Commercial Vehicle & Transportation Network Vehicle & Corporate-Piloted Vehicle \\
\hline 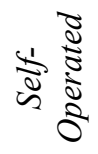 & Rental Vehicle & Peer-to-Peer Shared Vehicle & Personal Vehicle \\
\hline
\end{tabular}

Commercial VTOL vehicles, including helicopter airliner and air-taxis, have precedent but have struggled with their business models ${ }^{6}$, including air-based metropolitan mobility. From 1949 to 1979, New York Airways (NYA) was an intra-city commercial airline company that operated in New York City. It began as a mail and cargo service but in 1953, began scheduling passenger transportation. With headquarters at LaGuardia Airport in Flushing, New York, the VTOL aircraft (e.g. Sikorsky S-61L and Boeing Vertol 107 helicopters), could transport customers between several heliports on buildings in Manhattan, and the Newark and Idlewild (now JFK) airports. Trips could be completed in 10 minutes so passengers could arrive in Manhattan 40 minutes in advance of their ultimate airplane departure from Idlewild. NYA earned at least $\$ 3$ million each year from federal subsidies and fares ${ }^{7}$ but due to public response to several accidents over 15 years, operations were terminated ${ }^{8}$. The accidents were found to be caused by mechanical failures during takeoff or landing operations and led to deaths not only of passengers but also of bystanders at the heliport and pedestrians below the helipad in Manhattan.

While NYA ultimately was unsuccessful, there are other environments in which helicopter operations have been more sustainable. In São Paulo, Brazil, a combination of the high density of buildings with helipads ${ }^{9}$, heavy road traffic, and a customer base supporting regular air travel has created a thriving helicopter taxi industry ${ }^{10}$. Helicopter services out of Stavanger, Norway offer regular transportation between the mainland and offshore oil rigs ${ }^{11}$. However, even in these cases the air transportation remains a relatively expensive option.

High costs of the aircraft may be overcome with the commercial TNV approach (Table 1) through an anticipated high utilization rate since these vehicles are neither owned nor operated by the users. Such vehicles have been a successful model for on-demand ground transportation ${ }^{12}$. However, as will be discussed in a later section, there are differences between the concepts of operations proposed for aircraft versus cars that present challenges to scaling this model for larger markets. Additionally, recent research found that people surveyed in the United States preferred the 'personal vehicle' model of flying cars over ride-sharing options ${ }^{13}$. Keeping the costs and benefits of these different owner-operator models in mind will be important as new companies enter this market. One other significant area to be explored is the role of the pilot, in that such services could be provided by conventional air taxis but the increasing commercial investment in drones has raised the possibility of pilotless aircraft for passenger transport.

So, this question remains: in the $21^{\text {st }}$ century, will we see a Jetsons-like dream come true? Over the course of six months, our team conducted interviews with stakeholders working toward this answer to enable personal air mobility. Our analyses of stakeholders and vehicle safety functions uncovered three differing concepts of operations, each with distinct impetuses, implications, and timelines for the realization of ODM. Additional analysis of, regulations and technical challenges identified a set of key barriers to the implementation of ODM.

\section{Methods}

We took a systems-theoretic approach, analyzing the ODM system holistically and explicitly considering both the technical as well as sociotechnical aspects. We began by investigating the current state of the world to determine relevant stakeholders and the system boundaries. Once we identified stakeholders, we conducted interviews with many of them including companies currently developing on-demand personal autonomous aircraft. Leaders from 
Airbus $\mathrm{A}^{3}$, Ehang, Lilium Aviation, Kairos, Lockheed Martin-Sikorsky, Gryphon Sensors, Northeast Unmanned Aircraft System (UAS) Airspace Integration Research (NUAIR) Alliance, NASA Ames Research Center, Uber Technologies, FAA, and Pogojet all shared valuable time and knowledge to support our analyses. In this section, we will delve into our analyses of stakeholders and vehicle functions that were critical in formulating the various concepts for ODM proposed by the interviewees and refined by the authors. We follow this section with our analysis of the concepts of operations.

Once the system concepts were outlined, we conducted an initial identification of hazards to examine the system throughout its life cycle for inherent safety-related risks. Our focus was on those operational hazards that will be common to all aircraft, such as engine or communication failures. We then analyzed current regulatory and operational frameworks (e.g. Code of Federal Regulations 14 Parts 23, 91, and 135) to determine what presently limits the commercialization of ODM in aviation. We also studied proposed rules, including other international regulatory frameworks so that we understand how regulatory frameworks are evolving.

\section{A. Stakeholder Analysis}

As shown in Table 2, ODM original equipment manufacturer (OEM) stakeholders involve companies with long histories in aviation as well as newcomers. The startups are helping to drive interest and development in this space, although several OEMs with extensive research resources are also investing money in avionics for these concepts. Groups like the General Aviation Manufacturers Association (GAMA) or American Helicopter Society (AHS) are key stakeholders in building consensus towards industry standards. Their insights are valuable to decisions concerning operational parameters. Additionally, an important factor is public acceptance, therefore, consumers are major market actors and their safety is a primary concern of government regulatory bodies.

Governments and alliances are the stakeholders that influence or delay market entry and commercialization of vehicles and associated services. Alliances like NUAIR, for Northeast UAS Airspace Integration Research, and NASA's UAS Traffic Management (UTM) work to bring public and private parties together to realistically develop and test concepts and collaborate on broad solutions for advanced aviation. The FAA has historically prescribed rules but in the case of ODM has maintained the role of assessor, awaiting "pushes" from industry to determine the direction of regulation, with the ultimate intention of maintaining safe and efficient operations in the National Airspace System (NAS).

Table 2: Stakeholders

\begin{tabular}{|c|c|}
\hline Groups & Examples \\
\hline \multirow[t]{3}{*}{$\begin{array}{l}\text { Government \& } \\
\text { Alliances }\end{array}$} & $\begin{array}{l}\text { Regulators: Civil Aviation Administration of China; European Aviation Safety Agency (EASA); } \\
\text { FAA }^{+} \text {; NAVCanada }\end{array}$ \\
\hline & Researchers: Deutsches Zentrum für Luft- und Raumfahrt; European Space Agency; NASA ${ }^{+}$ \\
\hline & Consortia: NUAIR $^{+}$and other official UAS test sites $^{14}$; UAS Traffic Management ${ }^{+}$ \\
\hline \multirow[t]{3}{*}{ Market Actors } & Responders: Consumers \\
\hline & Service Providers: Kairos ${ }^{+}$; Uber ${ }^{+}$ \\
\hline & $\begin{array}{l}\text { Professional Advocates: AIAA; AHS; Aircraft Owners \& Pilots Association (AOPA); GAMA; } \\
\text { Society of Automotive Engineers }\end{array}$ \\
\hline \multirow[t]{2}{*}{$\begin{array}{l}\text { Original } \\
\text { Equipment } \\
\text { Manufacturers }\end{array}$} & $\begin{array}{l}\text { Vehicle Developers: AeroMobil; Airbus } \mathrm{A}^{3+} \text {; Airbus Helicopters; Ehang }{ }^{+} \text {; Hoversurf; Italdesign; } \\
\text { Jetpack Aviation; Joby Aviation; Kitty Hawk; Lilium Aviation }{ }^{+} \text {; Moller International; PAL-V; } \\
\text { Terrafugia; Urban Aeronautics; Volocopter; Xplorair; XTI Aircraft; Zee.Aero }\end{array}$ \\
\hline & $\begin{array}{l}\text { Avionics Developers: Boeing; Echodyne; Garmin; Gryphon Sensors }{ }^{+} \text {; Lockheed Martin- } \\
\text { Sikorsky }{ }^{+} \text {; Rockwell Collins }\end{array}$ \\
\hline
\end{tabular}

\section{B. Functional Analysis}

We used a framework, developed previously ${ }^{15}$ and summarized in Table 3, to help facilitate comparisons of concepts of operations (CONOPS) that differ significantly from current practice and regulation. The framework allowed us to assess key functions and sub-functions necessary to maintain vehicle safety, regardless of the system architecture designed. In addition, it was used to assess likely regulatory requirements and challenges in moving from current to future regulations. Ultimately new aircraft and operations will likely need to assure equivalent or better levels of safety (EBLS) while new regulations will need to accommodate the likely radically different allocation of functional responsibilities, capabilities, and locations of human and machine agents. 
Pilots and air traffic controllers have been historically responsible for maintaining aircraft safety and mitigating many rare and unexpected hazards ${ }^{16,17}$. However, depending on the system architecture of future ODM operations, any one of the eight high-level functional safety requirements in Table 3 may be allocated differently between humans and artificially intelligent machine operators. Detailed in the next section are the concepts of operations and function allocations for the three system architectures that emerged from the analyses.

Table 3: Functions to maintaining vehicle safety ${ }^{15}$

\begin{tabular}{|c|l|}
\hline Safety Function & \multicolumn{2}{|c|}{ Description } \\
\hline Maintain Safe Separation & $\begin{array}{l}\text { 1. Maintain safe separation from other participating vehicles, and do not create } \\
\text { excessive risk. Vehicles will be expected to behave per prescribed rules or behaviors. }\end{array}$ \\
\hline From other traffic & $\begin{array}{l}\text { 2. Maintain safe separation from fixed (terrain and road signs) and dynamic (animals } \\
\text { and pedestrians) hazards that are outside the "system" and that cannot reliably be } \\
\text { expected to share separation responsibilities. }\end{array}$ \\
\hline Maintain vehicle control & \multicolumn{2}{|l|}{$\begin{array}{l}\text { Nominal \& contingency } \\
\text { operations }\end{array}$} & $\begin{array}{l}\text { 3. Maintain vehicle control such that its future state and trajectory can be reliably } \\
\text { predicted and directed, even under adverse conditions such as ice and high winds. }\end{array}$ \\
\hline $\begin{array}{l}\text { Physical \& cyber } \\
\text { security }\end{array}$ & $\begin{array}{l}\text { 4. Maintain the physical and cyber security of the vehicle such that it can be } \\
\text { commanded or controlled only by authorized operators and the occupants are } \\
\text { protected from intentionally malicious harm. }\end{array}$ \\
\hline Maintain mission \& vehicle management \\
\hline Fuel management & $\begin{array}{l}\text { 5. Maintain sufficient energy to complete trip. Vehicle operators must be aware of } \\
\text { fuel requirements and energy availability onboard and/or along the way, such that } \\
\text { trips can be completed while satisfying any reserve requirement. }\end{array}$ \\
\hline Navigation & $\begin{array}{l}\text { 6. Maintain adequate navigation accuracy to safely complete the trip, including } \\
\text { position and infrastructure awareness (i.e., roadways or instrument procedures) such } \\
\text { that an appropriate route can be planned and followed. }\end{array}$ \\
\hline $\begin{array}{l}\text { Ride quality \& strategic } \\
\text { weather avoidance }\end{array}$ & $\begin{array}{l}\text { 7. Maintain adequate ride quality for passenger safety, including avoiding weather } \\
\text { and other conditions that could create discomfort, e.g., acceleration }>2 \text { g's is } \\
\text { considered objectionable under less than emergency conditions }{ }^{18} .\end{array}$ \\
\hline Systems management & $\begin{array}{l}\text { 8. The systems of the vehicle must be managed appropriately to maintain } \\
\text { performance and expected levels of safety. Subsystem failures may require altering } \\
\text { the current operation to maintain safety such as making a precautionary landing } \\
\text { should engine health become uncertain. }\end{array}$ \\
\hline
\end{tabular}

\section{Concepts of Operations}

Our area of inquiry was limited to short-range intra-urban Vertical Take-Off and Landing (VTOL) operations (e.g., $<100$ miles and tens of minutes of flight) and longer range flights between small airports (e.g., 200-500 miles at $\sim 200 \mathrm{mph}$ or flights up to 3 hours). We did not investigate large transport aircraft, either passenger or cargo. In this section, we provide an assessment of operational concepts current stakeholders are envisioning, and then consider what hazards and risks these concepts are likely to generate, including the risk of regulatory obstacles.

\section{A. Conventional Air Taxis}

This concept is closest to present-day on-demand, commercial air travel and intends to provide services between metropolitan hubs and suburbs using some version of a helipad. The vehicle would include at least two seats, one for a pilot and others for passengers. Trips may cover distances up to 300 miles at an altitude of 10,000 feet. Under this model, both inter- and intra-city transits are considered and would typically be used if the total door-to-door travel time is shorter than by car.

A typical trip (depicted in Figure 1), from the perspective of a single vehicle, would include eight phases with the ability to address contingencies that may arise throughout. Phase One of this operational concept would involve (1) a passenger requesting flight via a mobile application platform, (2) the mobile application platform referring the opportunity to an available pilot, (3) a pilot accepting the request, and (4) the app displaying the flight itinerary to both the passenger and the pilot interfaces once the passenger confirms the request.

Phase Two involves (1) the passenger and pilot arriving to the depot (which could be by air or by ground transportation). (2) The passenger and the pilot may each need to be verified through a security process. Once the 
pilot is verified, (3) the pilot completes a pre-flight checklist including a walk-around to verify the aircraft is safe and airworthy for operation.

Phase Three begins once the system components are all verified, then (1) the pilot ensures the passenger understands and follows safety instructions for embarking, (2) the pilot communicates with the dispatch center that systems are ready to go, (3) and the pilot transfers necessary information to air traffic control (ATC) to get a final approval/clearance on airspace access. (4) Dispatch remotely monitors the pad to ensure safety conditions are met for vertical takeoff and (5) ATC communicates with pilot to allow takeoff.

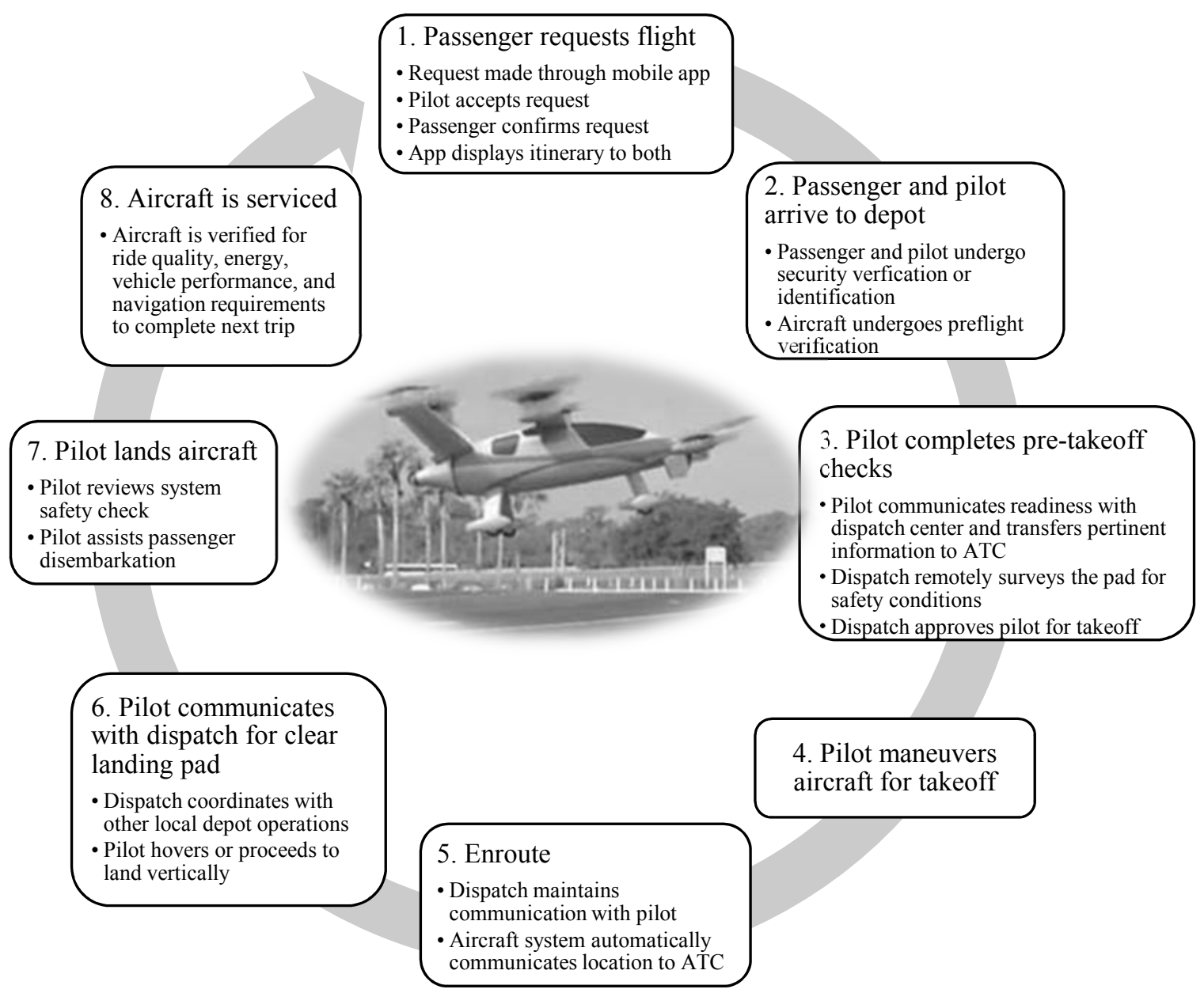

Figure 1: Concept of Operations for Conventional Air Taxi System

Phase Four involves the pilot maneuvering the aircraft takeoff such that (1) if one engine becomes inoperative, the aircraft can safely stop at the pad or (2) continue onto takeoff flight path with the required speed, climb out on the required gradients and go into cruise mode at the pre-specified height.

Phase Five begins once the aircraft has taken off. (1) The pilot receives navigational aids to direct the flight. (2) Dispatch center remains in communication with pilot while (3) the aircraft system automatically communicates location for ATC.

Phase Six arises as the aircraft approaches a certain distance from the destination depot, the (1) pilot communicates with ATC or dispatch to ensure the landing pad is cleared for use, (2) dispatch coordinates with other fleet vehicle operations, (3) pilot hovers or proceeds to land vertically.

In the case of emergency landings, the pilot would (1) be required to follow the instructions received in training and per the aircraft manual, (2) if possible, consult with dispatchers and/or ATC for additional insight, and (3) inform passenger to follow emergency procedures to prepare for landing.

If the aircraft is within closest range to the depot it took off from ("home base"), the pilot may be instructed to return to home base or an alternate landing site if home base is inaccessible due to weather or other issues. Under 
contingency conditions in which the aircraft is not closest to home base and is unable to reach the destination depot, the pilot would identify viable emergency landing locations while communicating with dispatch, ATC, and other local airspace/landing networks. However, if the contingency scenario involves pilot incapacitation, then the aircraft system would be equipped with a "deadman" switch of sorts to provide the passenger with an alternative escape option, which could include parachutes for the person or plane.

Phase Seven occurs once the pilot (1) has landed the aircraft on the pad, (2) goes through a system check for safe disembarkation of vehicle and (3) assists passenger to ensure all personal items are cleared, then (4) walks the passenger down a safe pathway to avoid any danger from the aircraft.

Phase Eight involves the aircraft being energized, cleaned (if needed) and verified through a maintenance check to ensure the next trip begins with ride quality, energy, vehicle performance, and navigation accuracy requirements to complete the projected trip.

Lilium Aviation ${ }^{19}$ is an example of a company taking this approach with its premier Jet. Thus far, they have validated sub-scale models of their vehicles.

\section{B. Revolutionary Vehicle Autonomy}

The previous CONOPS is based on current technology and does not assume that dramatic advances are made in control and automation technology. However, on the opposite end of the CONOPS spectrum, one could imagine developing an aircraft with full autonomy, particularly given the rapid reported progression of drones and driverless cars. The systems of this fully automated vehicle will need to perform functions of "aviation, navigation, and communication" ${ }^{20}$ which include flying the aircraft such that its attitude, angle, and flight paths are stabilized and guiding the aircraft laterally/vertically in the correct direction at a safe altitude while avoiding obstacles. This system may interface differently with ATC using a form of the unmanned aircraft systems traffic management (UTM) concept $^{21}$. For this CONOPS, dispatch operators could act in a supervisory role to manage the operations remotely and provide reversionary command capability in the event of unexpected scenarios that the autonomy cannot handle alone.

Phases One through Three of this operational concept are like those of conventional air taxis (Figure 1). However, in this case, aircraft would be interchangeable since the presence, crew hours, and training of a pilot are no longer constraints. From the verification to takeoff process, passengers and aircraft undergo the same checks as described earlier. In this case, though, automated technologies would be in control, to assist passengers with embarking and preparing for takeoff while remote dispatch supervises.

Phases Four and Five involve the aircraft self-piloting from vertical takeoff and onto a flightpath established by the dispatch center toward the destination depot. The dispatch center takes on a more active role, and maintains communication with the passenger, in addition to monitoring the vehicle progress and status. In Phase Six (the approach phase) the autonomous aircraft utilizes the destination depot's automated surveillance system and the digital fleet management system to determine if the landing pad is cleared for use. Phases Seven and Eight occur as earlier described except landing would be completely automated, and the disembarkation of passengers would require additional staff at the depot. Vehicle maintenance could be automated with robotic assistance and remote dispatch monitoring, but this is a futuristic and emerging area of research.

In the case of emergency landings, the autonomous aircraft would (1) inform the passenger to follow emergency procedures to prepare for landing or (2) inform the passenger of the pre-planned alternative escape option. The same decision tree as presented earlier for conventional pilots would be used to determine alternative landing sites, including using maps and computer vision to identify viable emergency landing locations while communicating with dispatch, ATC, and other local airspace/landing networks.

An example of this CONOPS is $\mathrm{A}^{3}$ 's Vahana project, scheduled to have a detailed design of the prototype in three years ${ }^{22,23}$. In addition, Ehang has already started organizing a command-and-control center to integrate remote management of "184" (their autonomous aerial vehicle for passenger transport). Similar to the dispatch center we describe here, the dispatchers would be responsible for monitoring flight conditions and maintaining communications with the passenger ${ }^{24}$.

\section{Evolutionary Vehicle Autonomy}

This concept would begin as the conventional air taxi discussed previously (CONOPS A) but over multiple development cycles would integrate increasing degrees of autonomy while the level of human control is decreased. Eventually, the pilot would be removed from the operations to transition into revolutionary full vehicle autonomy (CONOPS B). This transition phase is the focus of those aircraft developers building "optionally-piloted" vehicles which can fly themselves, but can also be flown by a human pilot under conditions that require such control (typically driven by regulatory constraints). 
For an optionally-piloted aircraft, Phase One and Two would happen as outlined in Figure 1. In Phase Three, the pilot's main responsibility would be to guide the embarking passenger. The pilot would supervise the vehicle takeoff process in Phase Four. By Phase Five, the aircraft flies itself, requiring the pilot to remain attentive as with current operations. The dispatch center would remain in communication with the human pilot while the aircraft automatically communicates its location to ATC. Once the aircraft automatically lands, the pilot goes through postflight checks to ensure safe disembarkation from vehicle.

Under contingency conditions, the pilot would be instructed to ensure the aircraft routes to the optimal depot. If an emergency landing is necessary, the pilot has the option of regaining control of the operations. However, if the contingency scenario involves pilot incapacitation, then the aircraft would provide the passenger with alternative escape options a noted in CONOPS A.

Terrafugia's "master plan" presents such an idea for a vehicle with a flexible platform for technologies including automatic ground collision detection that would over time enable greater levels of vehicle autonomy ${ }^{25}$. Joby Aviation promotes the vision of "hypercommuter" electric planes that would be operated by licensed pilots in a transportation network using small landing pads throughout a metropolitan area to shorten the daily travel time for passengers ${ }^{26}$. The company has been experimenting with increasing automation to ease piloting in the vehicle transition mode from vertical takeoff to forward flight ${ }^{27}$.

\section{Comparison of Human-Machine Function Allocations}

To distinguish dependencies within the three CONOPS described, the eight vehicle safety functions (Table 3) were mapped to roles. Table 4 shows that the safety of conventional air taxis is highly reliant on pilot performance. Operations with full vehicle autonomy depend more on the quality of artificially intelligent (AI) software for aircraft safety of flight, depot surveillance and fleet management to ensure that occupants are safe and secure from fixed and dynamic hazards. AI surveillance would be responsible for analyzing video feeds to monitor any movement at the depot and alert the human dispatchers of exceptional cases that warrant action. The AI fleet manager keeps track of each vehicle's health, location, trajectory, and other information pertinent to maintaining efficient business operations.

While both revolutionary and evolutionary vehicle autonomy systems have significant complexities, the latter provides the potential for operations to revert to trained pilots within the vehicle in the event of different contingency scenarios, making it a potentially safer option for development of automation. The evolutionary approach appears to bridge the gap between the conventional and revolutionary CONOPS, but the evolutionary vehicle autonomy architecture requires challenging human-machine teaming to maintain vehicle safety. Relying on a human to monitor as the safety backup is dangerous if they do not remain in-the-loop and have reduced situation awareness. Moreover, costs would likely be high since there are effectively two systems that must be designed in parallel. The focus presented here has been on individual vehicle safety, but from a broader system perspective, with each additional vehicle operating over a region, fulfilling these functions may increase workload for pilots, ATC or dispatchers involved, and therefore reduce their capacity to respond to emergency situations.

Table 4: Roles and responsibilities within the CONOPS

\begin{tabular}{|c|l|l|l|}
\hline \multirow{2}{*}{ Function } & \multicolumn{3}{|c|}{ System Architecture } \\
\cline { 2 - 4 } & \multicolumn{1}{|c|}{ Conventional } & \multicolumn{1}{|c|}{ Revolutionary Full Autonomy } & Evolutionary Vehicle Autonomy \\
\hline 1. & ATC; Dispatch & ATC; Autonomy & ATC; Dispatch; Autonomy \\
\hline 2. & Pilot; Dispatch & Dispatch; Autonomy; AI Surveillance & Autonomy; Dispatch \\
\hline 3. & Pilot & Autonomy & Autonomy; Pilot \\
\hline 4. & Pilot & Autonomy; AI Fleet Manager & Pilot \\
\hline 5. & Pilot & Autonomy; AI Fleet Manager & Autonomy; Pilot \\
\hline 6. & Pilot & Autonomy & Autonomy; Pilot \\
\hline 7. & Pilot & Autonomy & Pilot \\
\hline 8. & Pilot & Autonomy; AI Fleet Manager & Pilot \\
\hline
\end{tabular}

Each of the CONOPS are associated with unique technical and regulatory considerations, detailed in the next section, which ultimately affect their timeline to market. 


\section{Technical and Regulatory Challenges}

\section{A. Technical Hurdles}

The primary technical hurdles that arise for conventional air taxis for ODM revolve around the need for VTOL aircraft, especially those that expect to fly at speeds over 200 knots $^{28,29}$. Tiltrotor and tilt-wing aircraft provide the flexibility of helicopters in their takeoff and landing phases along with the high-speed cruise ability of fixed wing airplanes during forward flight. However, such an aircraft has yet to be certified for civil use. Certification of AgustaWestland's AW609, reportedly the first civilian tilt rotor aircraft, has been delayed pending on the outcomes of an accident investigation from $2015^{30}$. Also, the military's V-22, the most advanced tilt VTOL platform, has an accident rate almost three times that of commercial helicopters but similar to some other military helicopters with a similar mission like the CH-53E, ${ }^{31,32}$. Given the spotty safety record of such technologies, many technical challenges need to be addressed before such aircraft can be certified for human-piloted or autonomous commercial civil applications.

Distributed electric propulsion (DEP) has been suggested as one solution to some of the technical challenges in VTOL operations by using significantly advanced algorithms to control the torque and angle of multiple motors which would theoretically reduce mechanical complexity ${ }^{33-35}$. While such advances hold great promise, they represent a dramatic shift in propulsion technology with significant hardware and software elements that have never been certified outside experimental operations. Moreover, it is not clear when battery technology will be able to meet power demands given the need for relatively lightweight systems ${ }^{36,37}$. Given that conventional tiltrotor operations have yet to be certified, it may be an even taller order for such unproven technologies to gain certification for manned, optionally piloted, or autonomous passenger air vehicles. However, the reduction in mechanical complexity, a potential reduction in performance decrement due to the loss of an individual motor, and aerodynamic asymmetries alongside the increase in control authority from DEP are promising.

In addition to hurdles posed by major hardware and software advancements, the physical design of the aircraft may also pose a risk, or even perception of risk, to passengers attempting to embark/disembark from the aircraft. Some manufacturers envision multiple rotors surrounding the aircraft, including around the bottom of the vehicles. Therefore, strategies in operations and vehicle design will be required to ensure humans are not injured by the blades, and that the blades are not subject to damage from foreign objects.

Other infrastructure challenges will include the design of the takeoff and landing zones. Such sites will need to be free of static and dynamic obstructions and hazards, and will also need to be secure. Given electric aircraft rely on a stored energy source, charging stations will pose additional risks and restrictions on the depot infrastructure. For example, lithium-ion batteries are reactively flammable to changes in air and humidity conditions. Moreover, the depot facility should be equipped to support the size and weight of all possible aircraft combinations that might land at the heliport during operations. If depots are privately owned and managed, this challenge could be controlled.

The CONOPs describe one trip of one vehicle operating under any one of the three system architectures but the broader system is much more complex. A traffic management system that meets the FAA's ATC standards of communication is a major systems integration hurdle that must be overcome for safe and efficient operations in the NAS of any of the ODM CONOPs that scale beyond a few daily operations. This would require a coalition of industry leaders to agree on a reliable framework of traffic coordination. Local traffic management could be handled by an automatic system monitored by a remote operating center (ROC), which would be a separate entity from air traffic control. The ROC more closely resembles an airline dispatch center, but instead of providing advice, operators in the ROC would be able to command, redirect, or control the vehicles if needed. Such a system would require advanced levels of human supervisory control and artificial intelligence which currently have no precedent in the civil ATC system and thus represent a revolutionary development that would also need to be certified.

Lastly, cybersecurity for fully autonomous vehicles, or even partially autonomous aircraft, is a serious concern. Having remote takeover capabilities of such aircraft might improve the speed or likelihood of certification, i.e., moving the pilot from the aircraft into a ground control center. However, there are concerns that creating such a "backdoor" into the system would raise the risk of cyber-attacks.

\section{B. Regulatory Considerations}

Regulations in transportation are generally intended to ensure safety of vehicle occupants as well as the safety of people and property near vehicle operations. In addition, operational regulations help facilitate the orderly and efficient flow of vehicles through the transportation network. The Code of Federal Regulations Title 14, Chapter I, often referred to as the FARs, define, among other things, how aircraft, airman, airspace, general operating rules, and commercial operations are regulated. Of relevance to ODM are FARs pertaining to the certification and 
commercial operation of small (i.e. non-transport category) aircraft. These FARs include airworthiness standards for non-transport category airplanes and rotorcraft (e.g. Parts 23, 27); pilot certification (Part 61); general operating and flight rules (Part 91); and operating-requirements for on-demand operations conducted for compensation or hire (Part 135).

Alternative means of compliance must be proposed and accepted by the FAA if manufacturers or operators choose not to comply with the established FARs. Acceptable alternatives must provide an equivalent or better level of safety (EBLS) relative to current regulations and operations. Depending on the significance of a change and its potential impact on other aspects of the aviation system, changes may be approved relatively quickly, as might be the case if only non-legislative rules are considered (e.g. changes to the interpretation of a rule policy guidance for compliance with a rule). Or, if a proposed change involves modification of what are considered legislative or substantive rules, the process typically involves a formal rule making process ${ }^{38}$ which usually takes several years or longer to complete, involves the broader aviation community, and may end in a result different than originally desired.

The FARs have largely evolved over time and are generally based on historical experience and current practice. While there is a trend in the FAA toward less-prescriptive, performance and risk-based regulations - perhaps best exemplified by the recently revised Part $23^{39}$ that permits manufacturers' use of industry-consensus standards to develop inventive designs and reduce aircraft certification costs - the majority of FARs are generally based on a prescriptive approach, codified around current implementations and operations. The practical implications are that proposed concepts which significantly deviate from explicit and implicit FARs assumptions will have a much higher degree of certification risk and uncertainty than more conventional concepts.

As an example of these explicit and implicit requirements, consider that for the commercial air-taxi operations considered in this paper, the current FARs explicitly require a highly trained pilot in command (PIC) on-board each aircraft (e.g. Part $135.109 \&$.243). Further, many other applicable FARs implicitly assume the presence of this onboard PIC in specifying a variety of other capabilities and requirements of the overall system. For example, FAR 91.113 requires that an on-board pilot "see and avoid" other aircraft and FAR 23.210 presumes an on-board pilot will sense control-force feedbacks through physical controls such as a yoke. Perhaps proving ODM success with cargo planes or in rural environments, while potentially running parallel tests through optionally-piloted manned passenger services, could generate sufficient confidence with the FAA, as opposed to entirely new concepts of operations.

In general, most other parts of the world use similar frameworks in that they involve an integrated set of regulations defining requirements for the vehicle, pilots, general flight rules, and commercial operations. However, the process by which the rules are applied, interpreted or formally modified can be quite different around the globe. It is likely that early ODM innovators will conduct initial development and operations in countries willing to provide greater regulatory accommodation and flexibility.

There are several regulatory obstacles that must be overcome, regardless of the system architecture, for ODM to be fulfilled. One major hurdle in the move towards revolutionary autonomy will be the need for interpretations of the FARs to determine what the EBLS should be from artificial intelligence that replaces human operators. In such cases, more dramatic regulatory change will require OEMs to engage with stakeholders early and often to ensure that new policies are in line with technology development and market readiness.

\section{Timeline of Expectations}

Investments and efforts in ODM and related technologies have been moving at a frenetic pace. Since this research began in October 2016, we have seen a series of public announcements about unmanned aerial vehicle technologies, both big and small, as shown in Figure 2. Most announcements are extremely optimistic, such as promising real world flight demonstrations by July $2017^{40}$, with commercial services available by $2020^{37}$. However, several companies have missed their mark on past promises of further development related to ODM such as AeroMobil ${ }^{41}$.

Interestingly in other related news, many drone companies are facing financial and technical challenges, if not complete failure. As the drone industry consolidates and finds its niche within the global market (smaller than predictions have suggested), this raises concerns about the market viability and the projected commercialization timelines for vehicles that rely on such revolutionary technology development. There is generally great excitement and support for on-demand mobility in aviation, but there is still yet significant work to be done in research and development. Specifically, challenges like the certification of probabilistic reasoning algorithms, the humanmachine interaction design for vehicles with increasing autonomy, and certification of electric propulsion as wells as communications and coordination of fleet vehicles are barriers that must be overcome for commercial operations. 


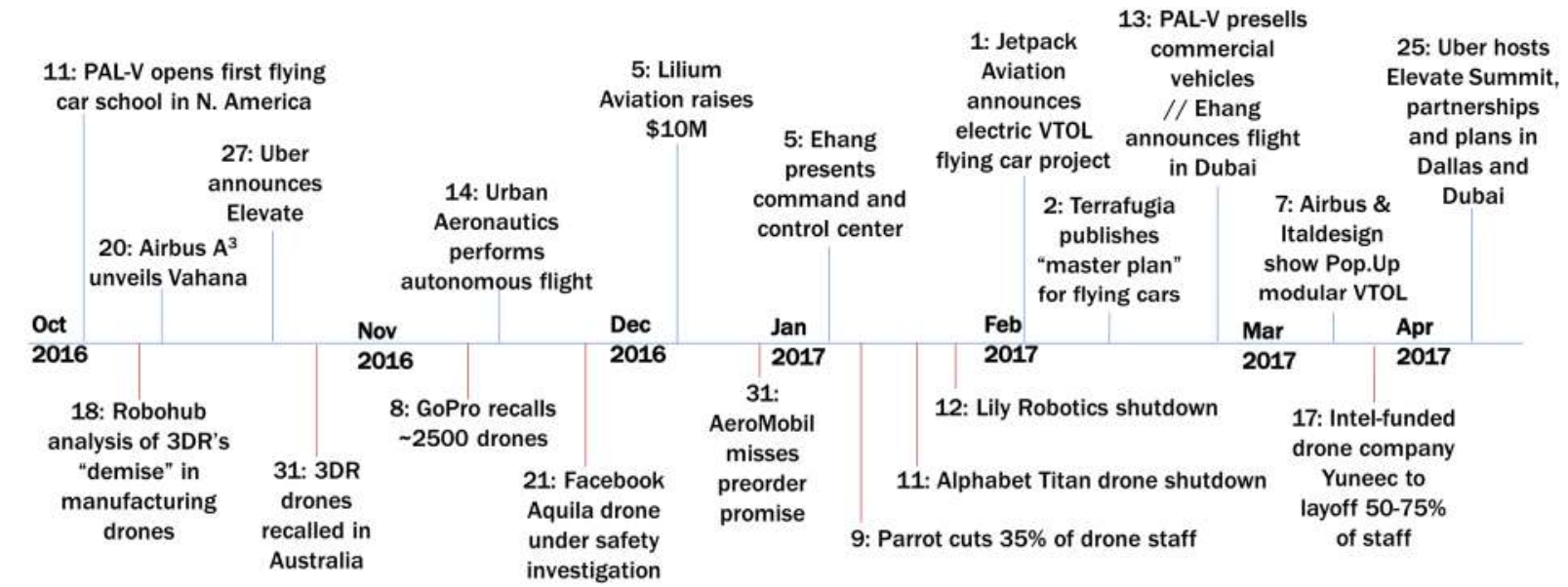

Figure 2: Timeline of public drone industry actions occurring between October 2016 and April 2017

In terms of when consumers in the United States could expect to see these technologies, such prognostications are difficult when technologies are rapidly developing. Conventional air taxis can be seen today as evidenced by services such as FlyOtto, which uses the network model to match potential customers with private charter operators (Part 135 certified) in general aviation aircraft. However, this concept for on-demand mobility must gain public acceptance as a viable option, and costs for such operations currently limit widespread market appeal.

According to the rapid technological development of some companies ${ }^{42}$, the revolutionary vehicle autonomy concept may already have a minimum viable product (i.e., a self-piloted aircraft capable of transporting a passenger on a designated flight path within trip constraints). However, considering the revolutionary sociotechnical framework that this would require, we believe it is likely that market readiness of such operations will be at least ten years in the future. There are projections that achieving full aircraft autonomy would take up to 30 years: perhaps ten for the human-proven model, ten more for the transition from evolutionary and optionally-piloted toward fully autonomous system-proven mode ${ }^{43-45}$. However, as noted previously, more flexible regulatory environments could lead to earlier deployment of such vehicle systems.

\section{Conclusions}

The well-established aviation market is under disruption by new players that are taking advantage of new business models and technologies in the development of short-range aerial transportation technologies. To this end, we identified three system concepts of operations for ODM air passenger transportation that range from operations that could happen in today's technology and regulatory environment (conventional) to one that is very futuristic (revolutionary full autonomy). While individuals could own such vehicles in the future, it is likely that transportation network vehicle schemes in which the occupants neither own nor operate the aircraft will be the dominant business model due to cost and complexity of operations. However, a recent survey found that people preferred the personal autonomous flying car that carried up to four people over pilot-operated ride-sharing vehicles ${ }^{13}$.

Small VTOL ODM aircraft promise transportation options that are more flexible than mass transit yet possibly more financially feasible than owning and operating personal air vehicles. VTOL enables the feasibility of intra-city ODM since the shift is away from GA airports and reduces connectivity needs to other forms of transportation. Passengers can potentially use their smartphones to request service when, where, and from whom they desire, without needing to plan. Such operations could circumvent traffic and reduce travel time without being dramatically more expensive than equivalent road travel ${ }^{46}$ (although should such services truly become options for everyday commuters, congestion could move from the ground to the air). Finally, the advent of AI technologies that enable vehicle autonomy present an opportunity for this service to scale by reducing reliance on human pilots and air traffic controllers.

Our future work will focus on potential divisions or overlapping of functions between an operator/passenger, the vehicle, and the requirements and need for a remote operations center (ROC). Technologies and regulations both may ultimately determine the rate and magnitude of success for these concepts. Given current public-private partnerships $^{40}$, industrial alliances ${ }^{47}$, and strategic investments ${ }^{19}$, the vision of accessible on-demand mobility in the skies is more mature than it has ever been, yet still has many challenges ahead. 


\section{Acknowledgments}

The authors would like to thank the National Institute of Aerospace and NASA Langley Research Center for supporting our work. Also, the authors thank those companies and agencies who participated in our stakeholder interviews.

\section{References}

Holmes, B. J., Durham, M. H., and Tarry, S. E., "Small Aircraft Transportation System Concept and Technologies," Journal of Aircraft, vol. 41, 2004, pp. 1-20.

Aircraft Owners and Pilots Association, "FAA Certificated Pilots" Available: https://www.aopa.org/about/generalaviation-statistics/faa-certificated-pilots.

Transportation Research Board, Future Flight: A Review of the Small Aircraft Transportation System Concept, Washington, D.C.: 2002.

FAA, Remote Pilot in Command Certification and Responsibilities, 2016.

Moore, J., "FlyOtto Connects Part 135 to the Masses," AOPA Available: https://www.aopa.org/news-and-media/allnews/2016/august/03/charter-network-now-online.

The Economist, "The return of the Eclipse," The Economist, Nov. 2011.

Guinn, H. W., "A study of the commercial helicopter passenger transportation industry," 1967.

Witkin, R., "Sikorsky to Pay New York Airways \$6 Million," The New York Times Available: http://www.nytimes.com/1983/05/29/nyregion/sikorsky-to-pay-new-york-airways-6-million.html.

de Voogt, A., Elevated City Helipads: Safety and Design, Maastricht, The Netherlands: 2008.

CAE Inc., "CAE and Líder Aviação Launch Sikorsky S-76 Training In São Paulo," defense-aerospace.com Available: http://www.defense-aerospace.com/articles-view/release/3/159355/cae\%2C-líder-aviacão-launch-s_92-training-in-saopaulo.html.

Lockheed Martin, "Sikorsky Thanks S-92® Helicopter Operators and Steps Up Support in Key North Sea Region" Available: http://www.lockheedmartin.com/us/news/press-releases/2016/september/160920-rms-sikorsky-thanks-s-92operators-and-steps-up-support-in-key-north-sea-region.html.

Greenblatt, J. B., and Shaheen, S., “Automated Vehicles, On-Demand Mobility, and Environmental Impacts," Current Sustainable/Renewable Energy Reports, vol. 2, 2015, pp. 74-81.

Sivak, M., and Schoettle, B., Report No. SWT-2017-8: A Survey of Public Opinion About Flying Cars, University of Michigan, Sustainable Worldwide Transportation: 2017.

Federal Aviation Administration, Unmanned Aircraft Systems Test Site Data Collection and Analysis, 2016.

Stouffer, V. L., and Goodrich, K. H., "State of the Art of Autonomous Platforms and Human-Machine Systems: Only a Fool Would Stand In the Way of Progress," 15th AIAA Aviation Technology, Integration, and Operations Conference, 2015, pp. 1-15.

6 Federal Aviation Administration, and Safety Research Corporation of America, “Airspace," Pilot's Handbook of Aeronautical Knowledge, United States Department of Transportation, Federal Aviation Administration, Airman Testing Standards Branch, 2016, p. 15.1-15.12.

Flight Deck Automation Working Group, Operational Use of Flight Path Management Systems, 2013.

Wyrick, B., and Brown, J. R., Medical facts for pilots, acceleration in aviation: G-Force, 2009.

Samavati, S., "Lilium Aviation raises $€ 10$ million from Atomico for vertical take-off electric plane," tech.eu.

Ververs, P. M., Understanding a Pilot's Tasks, Savoy, IL: 1998.

Kopardekar, P., Rios, J., Prevot, T., Johnson, M., Jung, J., and Robinson III, J. E., "UAS Traffic Management (UTM) Concept of Operations to Safely Enable Low Altitude Flight Operations," AIAA Aviation Technology, Integration, and Operations Conference, 2016, pp. 1-16.

"Project Vahana by A^ 3," 2014.

Lovering, Z., Vahana Configuration Trade Study - Part I, 2016.

Ehang, "Progress Updates of EHang 184 Autonomous Aerial Vehicle" Available: http://www.ehang.com/news/225.html.

Dietrich, C., "Making Flying Cars Practical: The Terrafugia Master Plan," CEO's Corner Available: https://www.terrafugia.com/making-flying-cars-practical-the-terrafugia-master-plan/.

Ashley, S., "Flying the Electric Skies," 2016.

Stoll, A. M., Stilson, E. V., Bevirt, J., and Sinha, P., "A Multifunctional Rotor Concept for Quiet and Efficient VTOL Aircraft," Aviation Technology, Integration, and Operations Conference, Los Angeles: American Institute of Aeronautics and Astronautics, 2013, pp. 1-7.

Defense Advanced Research Projects Agency, Vertical Takeoff and Landing Experimental Plane (VTOL X-Plane), Arlington, V.A.: 2013.

Dubois, T., and Huber, M., "New Rotorcraft 2012: Civil helicopter industry faces uncertain future," Aviation International News, 2012.

Head, E., "Third AW609 prototype returned to Leonardo," Vertical Mag Available: https:/www.verticalmag.com/news/third-aw609-prototype-returned-leonardo/.

International Helicopter Safety Team of the Commonwealth of Independent States, Helicopter Accidents: Statistics, 
Trends, and Causes, Louisville, Kentucky: 2016.

32 Seck, H. H., "Father of Marine Killed in V-22 Osprey Crash Plans to Sue," Military.com, 2016.

33 Moore, M. D., Distributed Electric Propulsion (DEP) Aircraft, 2012.

34 Stoll, A. M., Bevirt, J., Moore, M. D., Fredericks, W. J., and Borer, N. K., "Drag Reduction Through Distributed Electric Propulsion," AIAA Aviation Technology, Integration, and Operations Conference, 2014, pp. 1-10.

35 Aurora Flight Sciences, LightningStrike: Innovation for Runway Independence, Manassas, VA: 2016.

Holden, J., and Goel, N., Fast-Forwarding to a Future of On-Demand Urban Air Transportation, San Francisco: 2016.

Bradshaw, T., Hook, L., and Hollinger, P., "Flying car contenders taxi for take-off," Financial Times, Apr. 2017.

38 Dillingham, G. L., Aviation Rulemaking: Incomplete Implementation Impaired FAA's Reform Efforts, Washington, D.C.: 2001.

Federal Aviation Administration, Revision of Airworthiness Standards for Normal, Utility, Acrobatic, and Commuter Category Airplanes, 2016.

"EHang Partners with Dubai RTA to Boost Smart Transport" Available: http://www.ehang.com/news/248.html. flying-cars/.

42 Gambrell, J., "Up, up and away: Passenger-carrying drone to fly in Dubai," Associated Press, Feb. 2017.

43 Hsu, J., "Forget Flying Cars: Passenger Drones May Be Hovering Soon at a Location Near You," Scientific American, 2017.

$44 \quad$ Sabin, D., "Researchers Say Autonomous Air Taxis Are 10 to 15 Years Away," Inverse, 2017.

45 Aube, T., "Our self-flying car future," Tech Crunch, Dec. 2016.

46 Boyle, A., "NASA study : Flying air taxis could be as cheap as an Uber ride, and faster," GeekWire, Sep. 2015.

47 Whittle, R., "Soon you'll be able to go to work in a flying taxi," New York Post. 